OPEN ACCESS

Edited by:

Giacomo Cavallaro,

IRCCS Ca' Granda Foundation

Maggiore Policlinico Hospital, Italy

Reviewed by:

Tim Jancelewicz,

University of Tennessee Health

Science Center (UTHSC),

United States

Bernhard Resch,

Medical University of Graz, Austria

*Correspondence:

Thomas Schaible

thomas.schaible@umm.de

Specialty section:

This article was submitted to

Pediatric Critical Care,

a section of the journal

Frontiers in Pediatrics

Received: 03 June 2019

Accepted: 24 July 2019

Published: 08 August 2019

Citation:

Rafat N and Schaible T (2019)

Extracorporeal Membrane

Oxygenation in Congenital

Diaphragmatic Hernia.

Front. Pediatr. 7:336

doi: 10.3389/fped.2019.00336

\section{Extracorporeal Membrane Oxygenation in Congenital Diaphragmatic Hernia}

\author{
Neysan Rafat and Thomas Schaible* \\ Department of Neonatology, University Children's Hospital Mannheim, University of Heidelberg, Mannheim, Germany
}

Congenital diaphragmatic hernia $(\mathrm{CDH})$ is characterized by failure of diaphragmatic development with lung hypoplasia and persistent pulmonary hypertension of the newborn (PPHN). If conventional treatment with gentle ventilation and optimized vasoactive medication fails, extracorporeal membrane oxygenation (ECMO) may be considered. The benefits of ECMO in $\mathrm{CDH}$ are still controversial, since there are only few randomized trials demonstrating the advantages of this therapeutic option. At present, there is no precise prenatal and/or early postnatal prognostication parameter to predict reversibility of $\mathrm{PPHN}$ in $\mathrm{CDH}$ patients. Indications for initiating $\mathrm{ECMO}$ include either respiratory or circulatory parameters, which are also undergoing continuous refinement. Centers with higher case numbers and the availability of ECMO published promising survival rates, but data on long-term results, including morbidity and quality of life, are rare. Survival might be influenced by the timing of ECMO initiation and the timing of surgical repair. In this regard a trend toward early initiation of ECMO and early surgery on ECMO exists. The results concerning the cannulation modes are similar and a consensus on time limit for ECMO runs does not exist. The use of ECMO in $\mathrm{CDH}$ will continue to be evaluated, and prospective randomized trials and registry network are necessary to help answering the addressed questions of patient selection and management.

Keywords: congenital diaphragmatic hernia, extracorporeal membrane oxygenation, pulmonary hypertension, surgical repair, long-term outcome

\section{INTRODUCTION}

Congenital diaphragmatic hernia $(\mathrm{CDH})$ is currently the most common indication for extracorporeal membrane oxygenation (ECMO) in neonates (1). Survival rates reported by the extracorporeal life support organization (ELSO) have continued to drop in the modern era (2) and systematic reviews concerning a benefit of ECMO in $\mathrm{CDH}$ did not find an advantage for ECMO (3-5). However, some centers and networks have demonstrated an increase in survival rates in $\mathrm{CDH}$ with the employment of ECMO by retrospective analysis in their series (6). ECMO may perform as a true safety net when conventional treatment strategies fail or may only be a marketing strategy for a center to become a high-volume center with the positive side effect of increasing experience in the treatment of $\mathrm{CDH}$. By increasing experience in the treatment of $\mathrm{CDH}$, ECMO employment might be reduced, however, in some cases of $\mathrm{CDH}$, pulmonary hypertension is so severe that only ECMO support can provide a chance of survival. The pathophysiology of $\mathrm{CDH}$ includes lung hypoplasia and abnormal development of the pulmonary vasculature with hyper-reactivity which leads to persistent pulmonary hypertension of the newborn (PPHN) (1). 
Episodes of hypoxia and hypercapnia can exacerbate the PPHN, leading to severe morbidity and mortality. In patients who continue to have labile physiology and low preductal saturations despite optimal ventilation, inotropic and pulmonary vasodilatory support, the next intervention considered in the management of $\mathrm{CDH}$ is extracorporeal membrane oxygenation (ECMO), if available. We present a review of literature in this complex patient group and try to answer some questions about optimal time to start ECMO, recommended entry criteria, mode of ECMO, and timing of operation.

\section{PATHOPHYSIOLOGY IN CDH AND RATIONALE FOR ECMO}

In isolated $\mathrm{CDH}$ it seems possible to predict survival and need for ECMO and also chronic lung disease (CLD) by measuring the lung size by ultrasound or MRI. Liver herniation is also an independent risk factor for employment of ECMO (7). Data obtained by MRI seems to have lower interoperator variation and are easier to unify than data obtained by ultrasound. Categorization of severity was processed as previously described, and allows the comparison of results of different centers or ongoing studies investigating the effect of fetal tracheal occlusion (FETO) (8). As an example, we show our published data from 2006 concerning the prediction for ECMO in the group of left-sided $\mathrm{CDH}$ with liver up (Figure 1). Prognostic value in this group was only about $70 \%$, because we could not predict how severe the pulmonary hypertension would be (9). With an optimal delivery room management, severely affected patients with liver up will present with some signs of a honeymoon (preductal saturation $>90 \%$ ). That may be a reason for some optimism, since these patients with potential reversible pulmonary hypertension may benefit from ECMO. Avoiding stress, acidosis and severe hypoxemia and therefore crises of pulmonary hypertension reduces the need for ECMO. Surely some patients will be severely affected and do not have any sign of honeymoon, but an ongoing respiratory acidosis. In these cases, survival is impossible. But finding precisely the threshold for not offering ECMO is extremely difficult.

Using a multi-variate modeling to define the worst $10 \%$ of patients, Kays et al. included 172 consecutive inborn, prenatally diagnosed $\mathrm{CDH}$ patients in their analysis (10). Of the 19 worst patients, who were all aggressively resuscitated at birth and showed an average initial $\mathrm{pH}$ of 6.83 (at $1 \mathrm{~h}$ of life) with a $\mathrm{PCO}_{2}$ $>100,10$ of 16 patients, eligible for ECMO, survived to discharge (63\%) (10). These results are difficult to compare to our data because the underlying prenatal severity is not published. In contrast, in our experience a preductal saturation $<85 \%$ and/or arterial $\mathrm{PCO}_{2}>100$ after initial stabilization (at $1 \mathrm{~h}$ of life) is not compatible with survival despite early initiation of ECMO (within the first $4 \mathrm{~h}$ of life).

While evidence is missing for the necessity for employment of ECMO support, data from case series of ECMO centers offer convincing evidence of the potential for ECMO to rescue patients at the highly severe end of the $\mathrm{CDH}$ spectrum, a capability not well-documented for other treatment options besides ECMO so

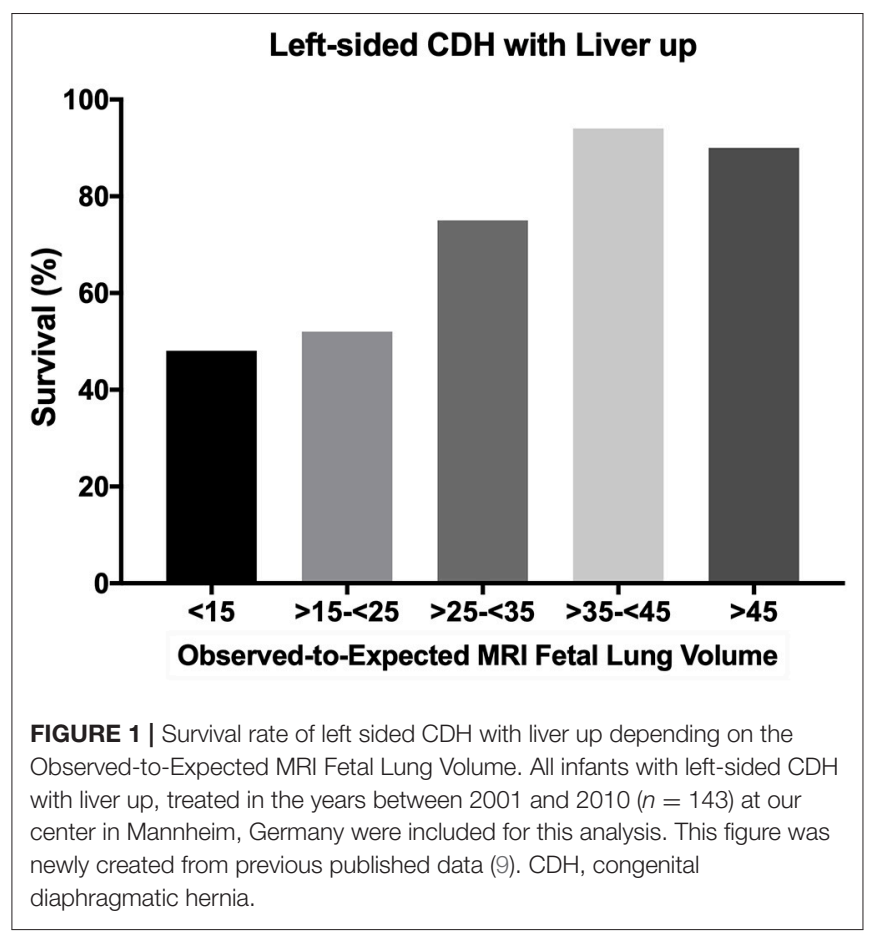

far (10). To understand the importance of ECMO support for selected cases of $\mathrm{CDH}$, we will look at the pathophysiology of pulmonary hypertension in more detail.

Reduced lung volume available for gas exchange may lead to hypoxemia and hypercarbia, and is one of the main pathological abnormalities that can determine the indication for ECMO. One difficulty is that severe lung hypoplasia is not currently reversible in the short term, and can make the possibility of weaning from ECMO difficult or impossible. PPHN can arise even in minor lung hypoplasia by causing a right-to-left shunt and persistent fetal circulation, which further exacerbates hypoxemia and hypercarbia. The vasculature of small pulmonary arteries is pathologically thickened and reaches far into distal airways. Any kind of distress as barotrauma, inflammation or cytokine release by surgical intervention may induce additional vasoconstriction of the small vessels. The presence of PPHN is a significant predictor and cause of morbidity, need for ECMO and mortality in $\mathrm{CDH}$ (11). Antenatal markers which accurately predict the degree of PPHN in $\mathrm{CDH}$, are not really known. To best address this challenge there are some suggestions, such as measuring antenatal pulmonary artery diameter, estimation of pulmonary perfusion by doppler measurements or left ventricular volume $(12,13)$.

Patients with either good or bad prognostication only based on antenatal lung volumes and ratios can have a discrepant clinical course. Postnatal clinical course could be a marker of severity of PPHN, with oxygenation index (OI) or combined parameters of ventilation and oxygenation (Wilford Hall/Santa Rosa Score) on day 1 predictive of outcome $(14,15)$. In postnatal therapy the institution of effective gentle ventilation from the very beginning in the delivery room, either by conventional ventilation or high frequency oscillatory ventilation (HFOV), 
is crucial. The VICI trial showed to some extent a benefit for conventional ventilation as the initial mode of ventilation in terms of a shorter ventilation time and a reduced need for ECMO, but not for mortality or BPD (16). The most widely used medication in PPHN management is inhaled nitric oxide (iNO). Inhaled nitric oxide (iNO) can improve oxygenation and reduce the acute need for ECMO in newborns with other causes of PPHN, but not conclusively in $\mathrm{CDH}$ (17). Nevertheless, the application of iNO in $\mathrm{CDH}$ is about $60 \%$ in reported case series (18).

Other treatment options like sildenafil or milrinone intravenously given in PPHN are applied to treat the condition in $\mathrm{CDH}$ with varying success (19). A European multi-center study is planned in order to investigate the effect of iNO vs. sildenafil after delivery. Systemic pressure should be maintained on normal values in order to avoid exacerbation of any right to left shunts.

Cardiac dysfunction resulting from the physiological derangements, PPHN or any associated congenital structural cardiac abnormality can complicate the clinical course (Figure 2). Poor cardiac output and impaired tissue oxygenation can ensue, and therefore serum lactate may be elevated and may work as an indication for employment of ECMO. In nearly all cases with suprasystemic pulmonary artery pressure and failure of reducing right-to-left shunts, a prostaglandin analog to open the ductus arteriosus and thereby unloading the right heart may help to stabilize the patient until ECMO is established.

Randomized controlled data on the role of ECMO in $\mathrm{CDH}$ is limited to two early ECMO studies and the UK ECMO trial (20-22). In the later trial, $\mathrm{CDH}$ patients were randomized at an oxygenation index of 40 to conventional ventilation vs. ECMO. From the $17 \mathrm{CDH}$ patients randomized to conventional management all died, while in the ECMO group 4 of 18 infants survived (0 vs. $22 \%$ survival) (22). In 2006 a systematic review of $\mathrm{ECMO}$ in $\mathrm{CDH}$ was published, identifying 658 publications of which 21 (2,043 patients) met entry criteria (23). Looking at the findings of these studies, the authors concluded that employment of ECMO was associated with a reduction in $\mathrm{CDH}$ mortality (23). Zalla et al. (24) reviewed a single center $\mathrm{CDH}$ experience, dividing 16 years of treatment into four eras. In the latter two eras ECMO support was then available. Post-hoc analysis suggested a $73 \%$ reduction in risk of death in the ECMO eras compared to the pre-ECMO eras despite increases in $\mathrm{CDH}$ disease severity (24). In a recent analysis of the CDH EURO Consortium at four high volume centers in Europe, there are also higher survival rates reported from ECMO centers compared to non-ECMO centers (25).

There is only little evidence about the impact of the location of the hernia on ECMO need and postnatal prognosis. Patients with right-sided $\mathrm{CDH}$ have been identified as requiring increased use of ECMO [54\% (26) and 71\% (27)], but had better than expected ECMO survival [80\% (26) and 83\% (27)] $(26,27)$. Recently published data from the $\mathrm{CDH}$ study group are contrary to the before mentioned single center experiences (28). The survival without ECMO in left-sided $\mathrm{CDH}$ was higher compared to right-sided $\mathrm{CDH}$ and the use of ECMO was comparably low in right-sided $\mathrm{CDH}$ (36\%) (28). The underlying pathophysiological mechanisms of these findings need to be investigated further. Some explanations for the different outcomes in right- vs. left-sided $\mathrm{CDH}$ have been suggested including the atypical dextroposition of the heart in left-sided $\mathrm{CDH}$ leading to adverse hemodynamic changes and an impaired cardiac function (27).

In general, improved survival without ECMO and also in ECMO centers is highly associated with the implementation of standardized treatment protocols, which mainly includes strategies to avoid ventilator associated lung injury (VALI) (29).

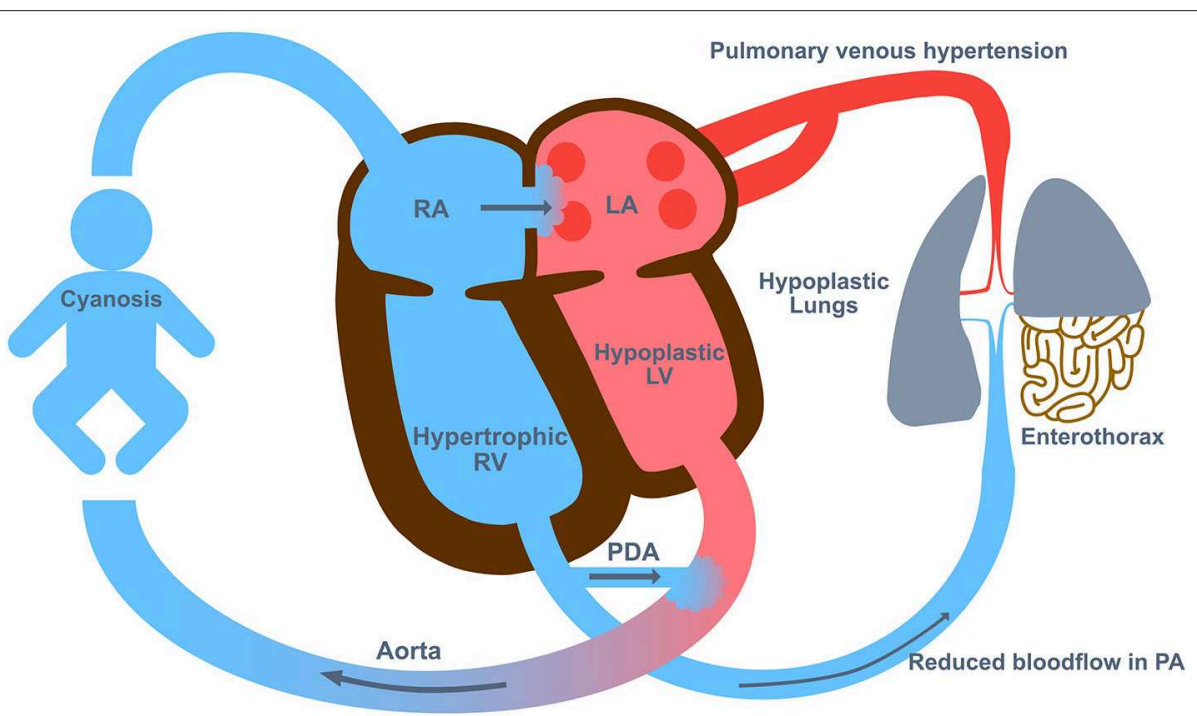

FIGURE 2 | The Pathophysiology in congenital diaphragmatic hernia (CDH). The pathophysiology of CDH includes lung hypoplasia and abnormal development of the pulmonary vasculature with hyper-reactivity which leads to persistent pulmonary hypertension of the newborn (PPHN). LA, left atrium; LV, left ventricle; PA, pulmonary artery; PDA, persistent ductus arteriosus; RA, right atrium; RV, right ventricle. 


\section{CDH ELSO INDICATIONS VS. CDH EURO CONSORTIUM INDICATIONS}

Entry criteria that accurately predict high mortality prior to the initiation of ECMO in infants with $\mathrm{CDH}$ have not been published (1). Various parameters have been used to predict those who benefit from ECMO (30-34), however, none of these criteria has been validated in multicenter studies (1). In the past, entry criteria suggested by ELSO for $\mathrm{CDH}$ patients included an oxygenation index $(\mathrm{OI})>40$ for $4 \mathrm{~h}$ or $\mathrm{PaO}_{2}<40$ for $2 \mathrm{~h}$ (30), which were general entry criteria for ECMO for neonates with pulmonary hypertension of any cause. In the newest edition of their guidelines (1), ELSO has adopted their entry criteria for infants with $\mathrm{CDH}$ also according to the recommendations suggested by the CDH EURO Consortium Consensus -2015 Update (35). They define the following indications to initiate ECMO support in $\mathrm{CDH}$ patients: hypoxia, defined as preductal saturations consistently $<80-85 \%$; acidosis, defined as metabolic (lactate $>5 \mathrm{mmol} / \mathrm{L}$ or $\mathrm{pH}<7.20$ ) or respiratory $(\mathrm{pH}<7.20$ due to hypercarbia); hypercarbia, defined as persistent $\mathrm{PaCO}_{2}$ $>70$ leading to $\mathrm{pH}<7.20$; or hypotension, defined as poor tissue perfusion, urine output $<0.5 \mathrm{~mL} / \mathrm{kg} / \mathrm{h}$ or unresponsive to IV fluid and inotropic support. In addition, many centers use a specific limit on ventilator settings to avoid ventilatorassociated lung injury (VALI) and transition to ECMO support when a patient does not respond appropriately (1). These include limiting the peak inspiratory pressure (PIP) $\left(\leq 26 \mathrm{~cm} \mathrm{H}_{2} \mathrm{O}\right.$, HFOV to a MAP of $14-15 \mathrm{~cm} \mathrm{H}_{2} \mathrm{O}$ ), and maintaining $\mathrm{pH}>7.20$ (usually $\mathrm{PaCO}_{2}<70 \mathrm{mmHg}$ ) (1). The only minor differences in the recommendation of the $\mathrm{CDH}$ EURO Consortium Consensus relate to the hypercarbia leading to a $\mathrm{pH}<7.15$ and the ventilator settings ( $\mathrm{PIP}>28 \mathrm{~cm} \mathrm{H}_{2} \mathrm{O}$ or $\mathrm{MAP}>17 \mathrm{~cm} \mathrm{H}_{2} \mathrm{O}$ ) as an entry criteria (35). There are no significant differences between the two guidelines, and the combined entry criteria for ECMO in $\mathrm{CDH}$ allow a center-depend individual decision.

Relative contraindications to initiating ECMO support in $\mathrm{CDH}$ patients are comprised of significant congenital anomalies (major cardiac anomalies), lethal chromosomal abnormalities or other lethal malformations, Grade III/IV intracranial hemorrhage, prolonged mechanical ventilation requiring prolonged high pressure, weight $<2 \mathrm{~kg}$ and gestational age $<34$ weeks (1). The last two criteria are due to technical problems of vascular access and the complications of prematurity. In general, prematurity is more common in patients with congenital anomalies and accordingly also in $\mathrm{CDH}$. Notably, preterm infants with $\mathrm{CDH}$ have an increased mortality compared to term infants (36).

\section{TIMING OF ECMO DEPLOYMENT: EARLY VS. LATE}

The data of the $\mathrm{CDH}$ Study Group highlight the trend toward employing ECMO earlier (before $\mathrm{CDH}$ repair) as a component of preoperative stabilization (Red Book). While the inclusion criteria for initiating ECMO have been described in detail, there is no data available on the influence of the time point, when
ECMO was initiated, on the morbidity and mortality in $\mathrm{CDH}$ patients. Many experts have the notion that the starting point of ECMO in $\mathrm{CDH}$ patients might be time-sensitive, since the responsivity of the pulmonary vasculature to pulmonary arterial hypertension treatment might be higher at the beginning and potentially reversible. If treated too late and complicated by the degree of pulmonary hypoplasia and VALI, the pulmonary hypertension can progress to right heart failure.

In our retrospective review of 321 neonates treated with ECMO from January 1987 to December 2006 at our center, we have already presented, that an early referral $(<24 \mathrm{~h})$ of $\mathrm{CDH}$ patients to the ECMO center correlated with an increased survival (6).

In a small cohort of patients with less than $15 \%$ predicted lung volume on antenatal scan who underwent EXIT to ECMO, no advantage in either survival or long-term morbidity could be demonstrated $(37,38)$. Although there are no randomized studies on EXIT to ECMO and these patients were not randomized, results led to the suggestion of little benefit for routine use (39).

\section{TYPE OF SUPPORT: VENO-VENOUS VS. VENO-ARTERIAL ECMO}

The mode of ECMO in $\mathrm{CDH}$, whether veno-venous (VV) or veno-arterial (VA), has not been demonstrated to affect survival so far, but the current available data is poorly controlled for underlying disease severity.

Veno-arterial (VA) ECMO is usually performed with an open cut-down technique where the right common carotid artery (CCA) and right internal jugular vein (IJV) are isolated and cannulated. Circuit flows are gradually increased to provide about 50 to $100 \mathrm{~mL} / \mathrm{kg} / \mathrm{min}$. Centrifugal ECMO circuits require smaller blood volumes for priming, but may be not as exact as roller-pump systems in providing low blood flows (the minimal possible blood flow without increased risk of clotting should be $30 \mathrm{~mL} / \mathrm{kg} \mathrm{KG}$ ). Also, for appropriate hemodynamic reloading of the right ventricle in VA ECMO, especially in the weaning or the idling phase at the end of the ECMO support time, the Mannheim experience suggests to apply lower blood flows. The appropriate cannula size is determined depending on the infant's weight (sizes available down to $8 \mathrm{Fr}$; hence the VA technique may be feasible for the smaller infants). VA ECMO may have some advantages in infants with cardiac dysfunction (unloading of the right ventricle and maintaining good systemic output). Due to the pathophysiology with preexisting lower blood flow through the small pulmonary vascular bed in severely affected $\mathrm{CDH}$ patients, we always used VA ECMO in $\mathrm{CDH}$ patients in Mannheim (Figure 3).

It is often feasible to repair the CCA at decannulation although the rates of long-term patency are unclear (the IJV is usually ligated). Our own data of repair CCAs showed patency in half of the cohort, stenosis in about one fourth and occlusion in the remaining fourth part of the cohort (40).

Cannulation to Veno-venous (VV) ECMO can be performed by open surgery or using an ultrasound-guided percutaneous technique to cannulate the IJV (thereby preserving the CCA). 


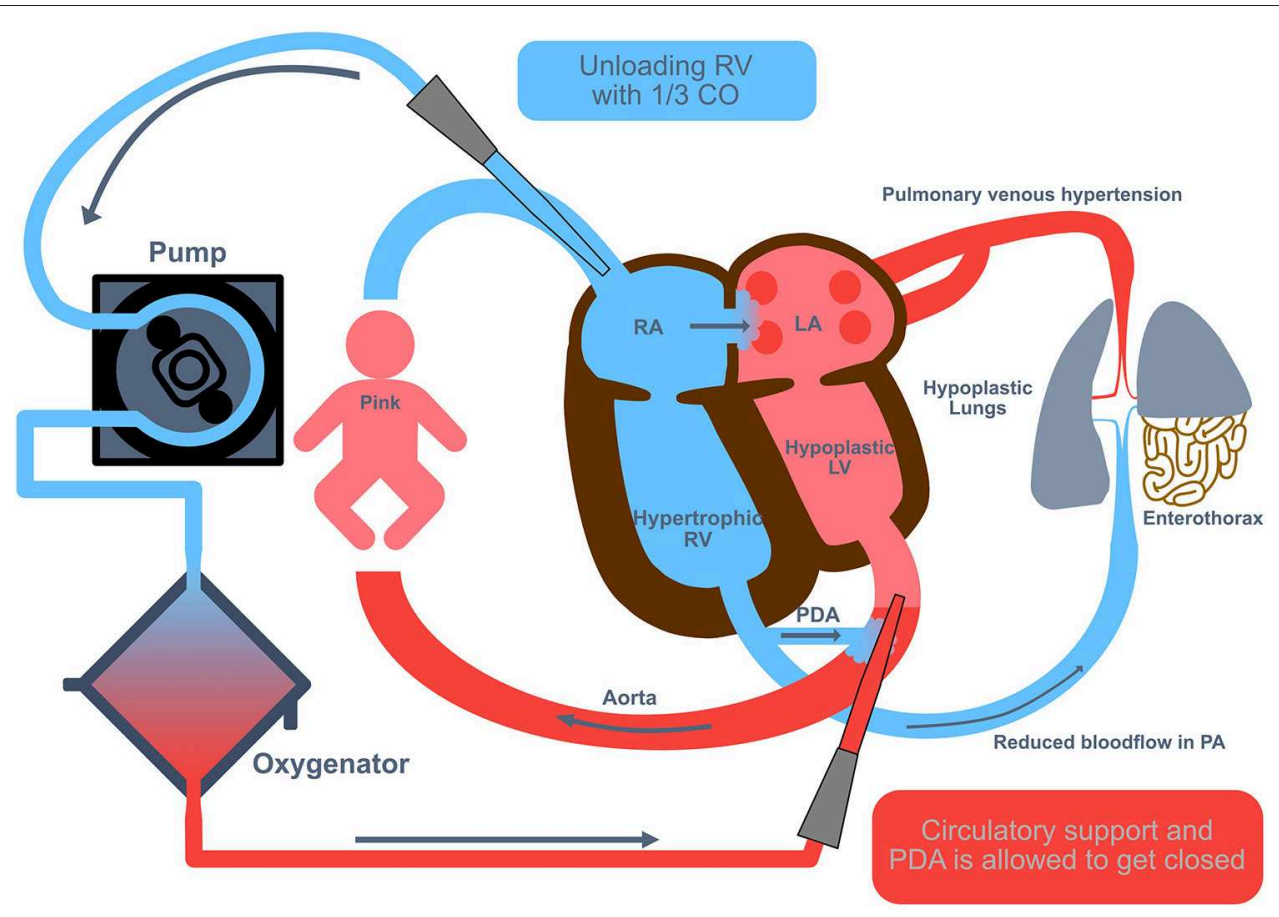

FIGURE 3 | Veno-arterial extracorporeal membrane oxygenation in congenital diaphragmatic hernia (CDH). Veno-arterial (VA) extracorporeal membrane oxygenation $(E C M O)$ is usually performed with an open cut-down technique where the right common carotid artery and right internal jugular vein are isolated and cannulated. Circuit flows are gradually increased to provide about 50 to $100 \mathrm{~mL} / \mathrm{kg} / \mathrm{min}$, equivalent to an unloading of the right ventricle with $1 / 3$ of the cardiac output. CO, cardiac output; LA, left atrium; LV, left ventricle; PA, pulmonary artery; PDA, persistent ductus arteriosus; RA, right atrium; RV, right ventricle.

Because the cannulae are dual-lumen catheter, the smallest size used is $12 \mathrm{Fr}$, which requires the weight of the infant to be $>2.5 \mathrm{~kg}$. A potential advantage of this technique is that hyperoxygenated blood is directed into the pulmonary artery and hence may reduce vascular resistance. But it is not clear whether a high amount of oxygen in the pulmonary vessels may lead to more inflammation via radical oxygen species (ROS). For unloading of the right heart, the duct should be open in the initial phase of VV- ECMO (Figure 4).

The VV-technique is dependent on satisfactory cardiac output and higher flows are usually required (often about 120 $\mathrm{mL} / \mathrm{kg} / \mathrm{min}$ ). Recirculation of oxygenated blood up the venous lumen makes the precise catheter position more critical.

The cumulative ELSO experience on this topic was reviewed in two reports $(41,42)$, the latter covering 15 years from 1991 to 2006 (42). The report showed that VA ECMO was used in $82 \%$, and VV ECMO only in $18 \%$ of the cases (42). Of the patients on VV ECMO 18\% required conversion to VA ECMO, with survival dropping from $54 \%(\mathrm{VV})$ to $44 \%$ (switch from VV to VA), compared to $50 \%$ when ECMO was initiated as VA (42).

Although a systematic review suggested that there was no overall advantage with either the VV or VA technique, there is a difference in preferred mode of cannulation between centers (43). VA ECMO seems to be the more popular of the two modes, according to the scientific reports and ECMO registries; presumably as VA ECMO may give the additional benefit in the presence of severe cardiac dysfunction. They reported that
VA was associated with slightly higher incidence of intracranial bleeding and seizure, while VV was associated with poorer renal perfusion. Size and vascular anatomy may sometimes dictate the mode used. Overall survival was similar between modes.

\section{TIMING OF SURGICAL INTERVENTION: BEFORE, DURING OR AFTER ECMO?}

Typically, the duration of ECMO support in $\mathrm{CDH}$ patients takes between 1 and 4 weeks. It has been demonstrated that prolonged need for ECMO is associated with both increased morbidity and mortality (44). In our experience an optimal duration of our preferred ECMO mode (VA) in Mannheim is 7-14 days with an average duration of 10 days. Two days after successful weaning from ECMO support, surgical repair of the CDH will be performed. This traditional approach is supported by some studies, which identified an increased survival rate, if repair could be delayed until ECMO support has been completed $(45,46)$. Weaning off ECMO includes a trial to clamp off ECMO for 10$15 \mathrm{~min}$, which is performed after 2 days with a very low flow of $30 \mathrm{ml} / \mathrm{kg} \mathrm{KG}$. The objective is achieving adequate oxygenation and ventilation $\left(\mathrm{pCO}_{2}<60 \mathrm{mmHg}\right)$ by a $\mathrm{FiO}_{2} \leq 0.5$ and gentle ventilation. In cases of weaning failure, we may prolong the ECMO support until a total of 21 days. If weaning fails after 21 days of ECMO support, we will offer compassionate/palliative care and a surgical repair will not be performed. 


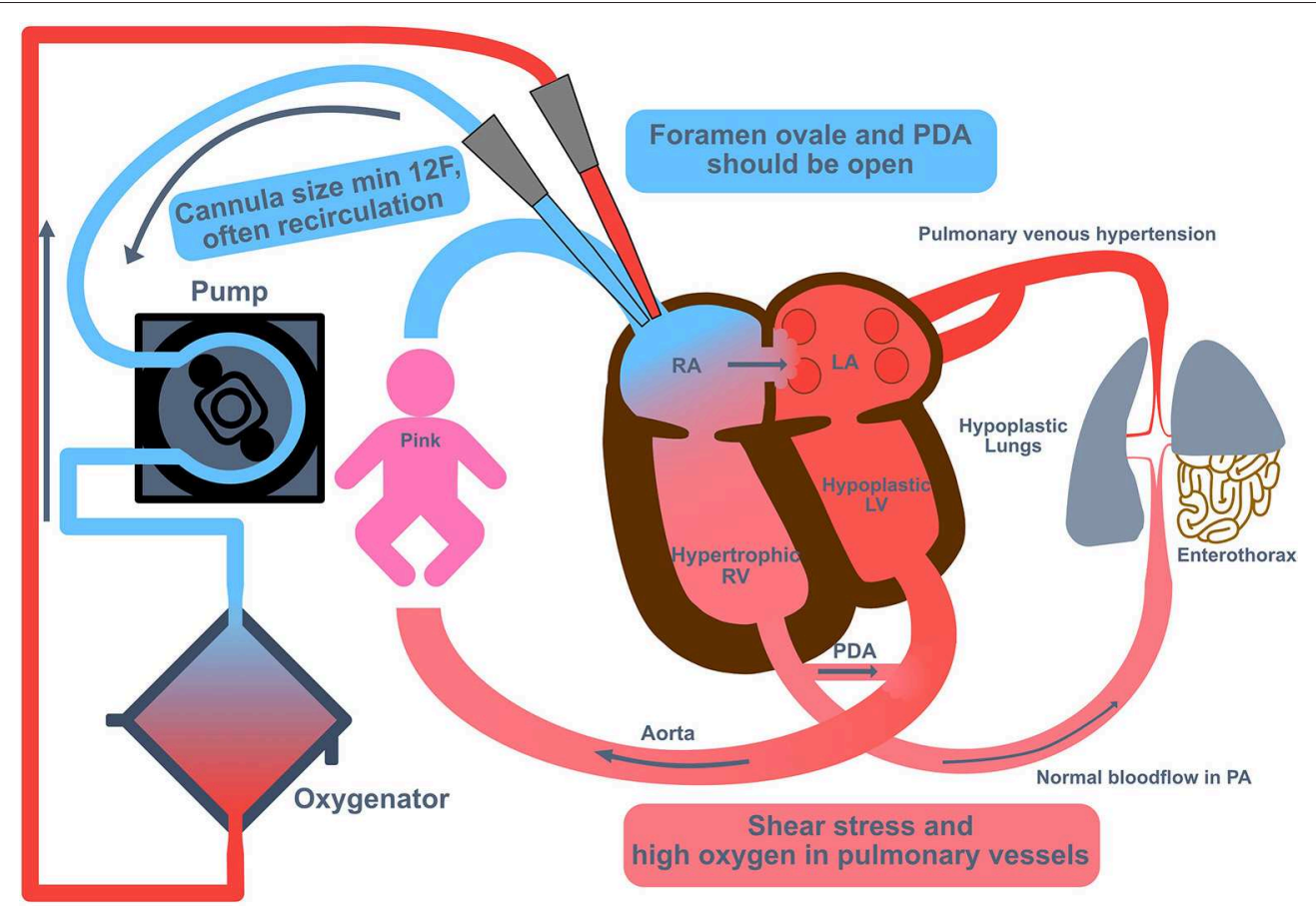

FIGURE 4 | Veno-venous extracorporeal membrane oxygenation in congenital diaphragmatic hernia (CDH). Cannulation to Veno-venous ( $\mathrm{V}$ ) extracorporeal membrane oxygenation (ECMO) can be performed by open surgery or using an ultrasound-guided percutaneous technique to cannulate the internal jugular vein (thereby preserving the common carotid artery). Because the cannulae are dual-lumen catheter, the smallest size used is $12 \mathrm{Fr}$, which requires the weight of the infant to be $>2.5 \mathrm{~kg}$. For unloading of the right heart, the duct should be open in the initial phase of W ECMO. LA, left atrium; LV, left ventricle; PA, pulmonary artery; PDA, persistent ductus arteriosus; $\mathrm{RA}$, right atrium; RV, right ventricle.

A main argument against surgical repair while on ECMO support is the higher incidence of bleeding. Complications from bleeding have, however, been reduced by careful anticoagulation management and the use of tranexamic acid perioperatively (47). Whether terminating treatment on ECMO without attempting surgical repair, might be a disadvantage and has not been systematically investigated. Some centers proclaim that surgical repair may increase the chances of survival, especially in the most severe forms of $\mathrm{CDH}$. Yoder et al. reported from the $\mathrm{CDH}$ Study Group, that patients with a preductal saturation $<85 \%$ in the first $24 \mathrm{~h}$ of life or before ECMO support, had an increased survival rate, if surgical repair was performed (44 vs. 23\%) (48). Due to this finding, surgical repair while on ECMO support was advocated. Theoretically, surgical repair while on ECMO support may improve respiratory function by restoring normal anatomy, and intestinal complications from delaying surgery (ischemia or volvulus) are possible (49).

Analyzing the studies about the timing of surgical repair in more detail, the duration of ECMO support was shorter in patients with surgical repair after ECMO (8.4 days) compared to patients with surgical correction while on ECMO (8.9 days) (45). Also, patients undergoing surgery after ECMO support seemed to have lower severity of disease (45).

Another strategy to avoid mortality due to late or non-repair on ECMO is "early" repair on ECMO. In the study of Dassinger et al. $34 \mathrm{CDH}$ patients underwent surgical repair while on ECMO at an average of $55 \mathrm{~h}$ after ECMO initiation (50). Only $9 \%$ of the patients suffered bleeding complications requiring intervention, and a total of $22(71 \%)$ survived (50). The same trend toward an early surgical repair while on ECMO is supported by the data of Fallon et al. (51).

A last approach of a very early surgical repair in a honeymoon-like period before decompensation was suggested by Kays et al. (52). They developed a multi-variate modeling, employing anatomic and physiologic markers of severityincluding prenatal lung measurements, liver position, birth physiology, and blood gas analysis data at $1 \mathrm{~h}$ after birth-to assess risk for ECMO at $1 \mathrm{~h}$ of life. Left-sided $\mathrm{CDH}$ patients with liver-up, which underwent surgical repair early before ECMO (mean time to surgery was $21 \mathrm{~h}$ ), had a survival rate of $95 \%$, compared to $65 \%$ in an equivalent group (left-sided CDH liverup), who underwent ECMO support without previous surgical repair (52).

The optimal timing of surgery for patients on ECMO support is difficult to ultimately establish, but it seems that there is a developing consensus that repair at an earlier stage (within 1 week) with careful management of perioperative risks, may help with either weaning off ECMO or decisions on withdrawal later, and potentially improves outcome. It seems that different patients benefit from different strategies, therefore, we have to learn to individualize some aspects of $\mathrm{CDH}$ treatment, e.g., the timing of surgical repair. 


\section{IMPROVING LONG-TERM OUTCOME OF CDH VIA STRUCTURED FOLLOW UP}

The only outcome criteria of the ELSO-registered neonates with $\mathrm{CDH}$ are: transfer to another hospital or survival to discharge (53). In future, more attention should be directed to short and long-term morbidity. ECMO centers may reflect not only their survival rate, but also changes in indications for ECMO and cognitive impairment as the major long-term deficit following neonatal ECMO (54). The most important issue after ECMO in CDH is neurodevelopment outcome. During initial treatment, cerebral bleeding or infarction should be evaluated closely by cranial ultrasound. For long-term evaluation, MRI including angiography seems to be helpful for reflection of the initial decisions and may help to relate the results to the complications (40). Intelligence, memory, attention, behavior, and concentration deficits are domains of interest in school age (54-57).

Looking at the pulmonary outcome due to lung hypoplasia, the degree of CLD represents a short term complication (58); lung function testing may serve as a parameter for lung function development after severe neonatal disease (59). Furthermore, structured echocardiographic investigations may guide treatment and prognosis of pulmonary hypertension in $\mathrm{CDH}$.

Surgical outcome parameters and complications after $\mathrm{CDH}$ repair include recurrence rates, feeding disorders and risk of ileus due to adhesions. In addition, further skeletal problems like chest wall deformations, funnel chest and scoliosis may occur. However, there is limited long-term outcome data in this regard.

Most follow-up studies in neonates and children who survived ECMO treatment have been cross-sectional, mono-center and in small study populations. With the current shift toward long-term multidisciplinary evaluations, observational follow-up-programs should be transferred toward risk stratification (60).

\section{CONCLUSION}

In conclusion, the use of ECMO in $\mathrm{CDH}$ remains controversial. While many centers have demonstrated very good survival,

\section{REFERENCES}

1. Brogan T V., Lequier L, Lorusso R, MacLaren G, Peek G, editors. Congenital diaphragmatic hernia and ECMO. In: Extracorporeal Life Support: The ELSO Red Book 5th Edition. Ann Arbor, MI: ELSO (2017). p. 137-43.

2. Turek JW, Nellis JR, Sherwood BG, Kotagal M, Mesher AL, Thiagarajan $\mathrm{RR}$, et al. Shifting risks and conflicting outcomes-ECMO for neonates with congenital diaphragmatic hernia in the modern era. J Pediatr. (2017) 190:163-8.e4. doi: 10.1016/j.jpeds.2017.08.010

3. Wilson JM, Lund DP, Lillehei CW, O'Rourke PP, Vacanti JP. Delayed repair and preoperative ECMO does not improve survival in high-risk congenital diaphragmatic hernia. J Pediatr Surg. (1992) 27:368-72; discussion 373-5. doi: 10.1016/0022-3468(92)90863-3

4. Wilson JM, Lund DP, Lillehei CW, Vacanti JP. Congenital diaphragmatic hernia-a tale of two cities: the Boston experience. J Pediatr Surg. (1997) 32:401-5. doi: 10.1016/S0022-3468(97)90590-X

5. Azarow K, Messineo A, Pearl R, Filler R, Barker G, Bohn D. Congenital diaphragmatic hernia-a tale of two cities: the Toronto experience. J Pediatr Surg. (1997) 32:395-400. doi: 10.1016/S0022-3468(97)90589-3 utilizing minimal to no ECMO in $\mathrm{CDH}$, the highest overall survival rates are reported by centers that employ ECMO, and whose patient populations likely also include the sickest patients. Due to the exceptional potential of ECMO to rescue $\mathrm{CDH}$ patients with profound pulmonary hypoplasia, the role of ECMO in severe $\mathrm{CDH}$ seems protected. The significance of surgical repair in attaining survival of patients with $\mathrm{CDH}$, especially of those on the more severe end of the spectrum, cannot be overstated. While surgical repair after ECMO works well for those that successfully wean from ECMO, an early repair strategy on or before ECMO might potentially increase survival.

Based on the presented data and significant professional experience with $\mathrm{CDH}$ care, we feel confident that ECMO improves survival potential in more severe $\mathrm{CDH}$ compared to currently available non-ECMO techniques. Improving $\mathrm{CDH}$ survival is still a major goal and since the majority of deaths occur in those more severely affected, improving outcomes in those $\mathrm{CDH}$ patients treated with ECMO is essential. However, mortality should not be the only focus and parameter when proclaiming the importance of ECMO in $\mathrm{CDH}$ treatment. More research is needed to assess the morbidity of $\mathrm{CDH}$ patients after ECMO support and their long-term outcome.

In our opinion, factors which contribute to ongoing improvement, include having updated standardized postnatal treatment guidelines and participation in networks, further referrals to high-volume center with increasing experience in the treatment of $\mathrm{CDH}$ and severity-specific management.

\section{AUTHOR CONTRIBUTIONS}

NR and TS contributed equally to the concept and drafting of the article. Both authors approved the final version of the article.

\section{ACKNOWLEDGMENTS}

We are thankful to the CDH EURO Consortium for fruitful discussions on this topic.

6. Schaible T, Hermle D, Loersch F, Demirakca S, Reinshagen K, Varnholt V. A 20-year experience on neonatal extracorporeal membrane oxygenation in a referral center. Intens Care Med. (2010) 36:1229-34. doi: 10.1007/s00134-010-1886-5

7. Russo FM, Eastwood MP, Keijzer R, Al-Maary J, Toelen J, Van Mieghem $\mathrm{T}$, et al. Lung size and liver herniation predict need for extracorporeal membrane oxygenation but not pulmonary hypertension in isolated congenital diaphragmatic hernia: systematic review and meta-analysis. Ultrasound Obstet Gynecol. (2017) 49:704-13. doi: 10.1002/uog. 16000

8. Deprest J, Brady P, Nicolaides K, Benachi A, Berg C, Vermeesch J, et al. Prenatal management of the fetus with isolated congenital diaphragmatic hernia in the era of the TOTAL trial. Semin Fetal Neonatal Med. (2014) 19:338-48. doi: 10.1016/j.siny.2014.09.006

9. Kastenholz KE, Weis M, Hagelstein C, Weiss C, Kehl S, Schaible T, et al. Correlation of observed-to-expected MRI fetal lung volume and ultrasound lung-to-head ratio at different gestational times in fetuses with congenital diaphragmatic hernia. Am J Roentgenol. (2016) 206:856-66. doi: 10.2214/AJR.15.15018 
10. Kays DW, Islam S, Perkins JM, Larson SD, Taylor JA, Talbert JL. Outcomes in the physiologically most severe congenital diaphragmatic hernia (CDH) patients: whom should we treat? J Pediatr Surg. (2015) 50:893-7. doi: 10.1016/j.jpedsurg.2015.03.005

11. Wynn J, Krishnan U, Aspelund G, Zhang Y, Duong J, Stolar CJH, et al. Outcomes of congenital diaphragmatic hernia in the modern era of management. J Pediatr. (2013) 163:114-9.e1. doi: 10.1016/j.jpeds.2012. 12.036

12. Ruano R, Aubry M-C, Barthe B, Mitanchez D, Dumez Y, Benachi A. Predicting perinatal outcome in isolated congenital diaphragmatic hernia using fetal pulmonary artery diameters. J Pediatr Surg. (2008) 43:606-11. doi: 10.1016/j.jpedsurg.2007.12.003

13. Vogel M, McElhinney DB, Marcus E, Morash D, Jennings RW, Tworetzky W. Significance and outcome of left heart hypoplasia in fetal congenital diaphragmatic hernia. Ultrasound Obstet Gynecol. (2010) 35:310-7. doi: 10.1002/uog.7497

14. Ruttenstock E, Wright N, Barrena S, Krickhahn A, Castellani C, Desai AP, et al. Best oxygenation index on day 1: a reliable marker for outcome and survival in infants with congenital diaphragmatic hernia. Eur J Pediatr Surg. (2015) 25:3-8. doi: 10.1055/s-0034-1393960

15. Hoffman SB, Massaro AN, Gingalewski C, Lou SB. Survival in congenital diaphragmatic hernia: use of predictive equations in the ECMO population. Neonatology. (2011) 99:258-65. doi: 10.1159/000319064

16. Snoek KG, Capolupo I, van Rosmalen J, Hout Lde J, Vijfhuize S, Greenough A, et al. Conventional mechanical ventilation versus high-frequency oscillatory ventilation for congenital diaphragmatic hernia. Ann Surg. (2016) 263:867-74. doi: 10.1097/SLA.0000000000001533

17. Barrington KJ, Finer N, Pennaforte T, Altit G. Nitric oxide for respiratory failure in infants born at or near term. Cochrane Database Syst Rev. (2017) 1:CD000399. doi: 10.1002/14651858.CD000399.pub3

18. Putnam LR, Tsao K, Morini F, Lally PA, Miller CC, Lally KP, et al. Evaluation of variability in inhaled nitric oxide use and pulmonary hypertension in patients with congenital diaphragmatic hernia. JAMA Pediatr. (2016) 170:1188. doi: 10.1001/jamapediatrics.2016.2023

19. Pandya KA, Puligandla PS. Pulmonary hypertension management in neonates. Semin Pediatr Surg. (2015) 24:12-6. doi: 10.1053/j.sempedsurg.2014.11.003

20. Bartlett R, Gazzaniga A, Toomasian J, Coran A, Roloff D, Rucker R. Extracorporeal Membrane Oxygenation (ECMO) in neonatal respiratory failure. 100 cases. Ann Surg. (1986) 204:236-45. doi: 10.1097/00000658-198609000-00003

21. Schumacher RE, Roloff DW, Chapman R, Snedecor S, Bartlett RH. Extracorporeal membrane oxygenation in term newborns. A prospective cost-benefit analysis. ASAIO J. (1993) 39:873-9. doi: 10.1097/00002480-199310000-00010

22. UK collaborative randomised trial of neonatal extracorporeal membrane oxygenation. UK Collaborative ECMO Trail Group. Lancet. (1996) 348:75-82. doi: 10.1016/S0140-6736(96)04100-1

23. Morini F, Goldman A, Pierro A. Extracorporeal membrane oxygenation in infants with congenital diaphragmatic hernia: a systematic review of the evidence. Eur J Pediatr Surg. (2006) 16:385-91. doi: 10.1055/s-2006-924751

24. Zalla JM, Stoddard GJ, Yoder BA. Improved mortality rate for congenital diaphragmatic hernia in the modern era of management: 15 year experience in a single institution. J Pediatr Surg. (2015) 50:524-7. doi: 10.1016/j.jpedsurg.2014.11.002

25. Snoek KG, Greenough A, van Rosmalen J, Capolupo I, Schaible T, Ali $\mathrm{K}$, et al. Congenital diaphragmatic hernia: 10-year evaluation of survival, extracorporeal membrane oxygenation, and foetoscopic endotracheal occlusion in four high-volume centres. Neonatology. (2018) 113:63-8. doi: 10.1159/000480451

26. Bryner BS, Kim AC, Khouri JS, Drongowski RA, Bruch SW, Hirschl RB, et al. Right-sided congenital diaphragmatic hernia: high utilization of extracorporeal membrane oxygenation and high survival. J Pediatr Surg. (2009) 44:883-7. doi: 10.1016/j.jpedsurg.2009. 01.037

27. Schaible T, Kohl T, Reinshagen K, Brade J, Neff KW, Stressig R, et al. Rightversus left-sided congenital diaphragmatic hernia. Pediatr Crit Care Med. (2012) 13:66-71. doi: 10.1097/PCC.0b013e3182192aa9
28. Burgos CM, Frenckner B, Luco M, Harting MT, Lally PA, Lally KP, et al. Right versus left congenital diaphragmatic hernia - What's the difference? J Pediatr Surg. (2018) 53:113-7. doi: 10.1016/j.jpedsurg.2017.10.027

29. van den Hout L, Schaible T, Cohen-Overbeek TE, Hop W, Siemer J, van de Ven K, et al. Actual outcome in infants with congenital diaphragmatic hernia: the role of a standardized postnatal treatment protocol. Fetal Diagn Ther. (2011) 29:55-63. doi: 10.1159/000322694

30. Sebald M, Friedlich P, Burns C, Stein J, Noori S, Ramanathan R, et al. Risk of need for extracorporeal membrane oxygenation support in neonates with congenital diaphragmatic hernia treated with inhaled nitric oxide. J Perinatol. (2004) 24:143-6. doi: 10.1038/sj.jp.7211033

31. Somaschini M, Locatelli G, Salvoni L, Bellan C, Colombo A. Impact of new treatments for respiratory failure on outcome of infants with congenital diaphragmatic hernia. Eur J Pediatr. (1999) 158:780-4. doi: $10.1007 / \mathrm{s} 004310051203$

32. Nagaya M, Kato J, Niimi N, Tanaka S, Tanaka T. Analysis of patients with congenital diaphragmatic hernia requiring pre-operative extracorporeal membrane oxygenation (ECMO). Pediatr Surg Int. (1998) 14:25-9. doi: $10.1007 / \mathrm{s} 003830050428$

33. vd Staak FH, Thiesbrummel A, de Haan AF, Oeseburg B, Geven WB, Festen C. Do we use the right entry criteria for extracorporeal membrane oxygenation in congenital diaphragmatic hernia? J Pediatr Surg. (1993) 28:1003-5. doi: 10.1016/0022-3468(93)90502-C

34. Howell CG, Hatley RM, Boedy RF, Rogers DM, Kanto WP, Parrish RA. Recent experience with diaphragmatic hernia and ECMO. Ann Surg. (1990) 211:793-7; discussion 797-8.

35. Snoek KG, Reiss IKM, Greenough A, Capolupo I, Urlesberger B, Wessel L, et al. Standardized postnatal management of infants with congenital diaphragmatic hernia in Europe: the CDH EURO Consortium Consensus 2015 Update. Neonatology. (2016) 110:66-74. doi: 10.1159/000444210

36. Tsao K, Allison ND, Harting MT, Lally PA, Lally KP. Congenital diaphragmatic hernia in the preterm infant. Surgery. (2010) 148:404-10. doi: 10.1016/j.surg.2010.03.018

37. Shieh HF, Wilson JM, Sheils CA, Smithers CJ, Kharasch VS, Becker $\mathrm{RE}$, et al. Does the ex utero intrapartum treatment to extracorporeal membrane oxygenation procedure change morbidity outcomes for high-risk congenital diaphragmatic hernia survivors? J Pediatr Surg. (2017) 52:22-5. doi: 10.1016/j.jpedsurg.2016.10.010

38. Stoffan AP, Wilson JM, Jennings RW, Wilkins-Haug LE, Buchmiller TL. Does the ex utero intrapartum treatment to extracorporeal membrane oxygenation procedure change outcomes for high-risk patients with congenital diaphragmatic hernia? J Pediatr Surg. (2012) 47:1053-7. doi: 10.1016/j.jpedsurg.2012.03.004

39. McHoney M, Hammond P. Role of ECMO in congenital diaphragmatic hernia. Arch Dis Child Fetal Neonatal Ed. (2018) 103:F178-81. doi: 10.1136/archdischild-2016-311707

40. Buesing KA, Kilian AK, Schaible T, Loff S, Sumargo S, Neff KW. Extracorporeal membrane oxygenation in infants with congenital diaphragmatic hernia: follow-up MRI evaluating carotid artery reocclusion and neurologic outcome. AJR Am J Roentgenol. (2007) 188:1636-42. doi: 10.2214/AJR.06.1319

41. Dimmitt RA, Moss RL, Rhine WD, Benitz WE, Henry MC, Vanmeurs KP. Venoarterial versus venovenous extracorporeal membrane oxygenation in congenital diaphragmatic hernia: the Extracorporeal Life Support Organization Registry, 1990-1999. J Pediatr Surg. (2001) 36:1199-204. doi: 10.1053/jpsu.2001.25762

42. Guner YS, Khemani RG, Qureshi FG, Wee CP, Austin MT, Dorey F, et al. Outcome analysis of neonates with congenital diaphragmatic hernia treated with venovenous vs venoarterial extracorporeal membrane oxygenation. $J$ Pediatr Surg. (2009) 44:1691-701. doi: 10.1016/j.jpedsurg.2009.01.017

43. Puligandla PS, Grabowski J, Austin M, Hedrick H, Renaud E, Arnold M, et al. Management of congenital diaphragmatic hernia: a systematic review from the APSA outcomes and evidence based practice committee. J Pediatr Surg. (2015) 50:1958-70. doi: 10.1016/j.jpedsurg.2015.09.010

44. Seetharamaiah R, Younger JG, Bartlett RH, Hirschl RB, Congenital Diaphragmatic Hernia Study Group. Factors associated with survival in infants with congenital diaphragmatic hernia requiring extracorporeal membrane oxygenation: a report from the Congenital 
Diaphragmatic Hernia Study Group. J Pediatr Surg. (2009) 44:1315-21. doi: 10.1016/j.jpedsurg.2008.12.021

45. Congenital Diaphragmatic Hernia Study Group, Bryner BS, West BT, Hirschl RB, Drongowski RA, Lally KP, et al. Congenital diaphragmatic hernia requiring extracorporeal membrane oxygenation: does timing of repair matter? J Pediatr Surg. (2009) 44:1165-71; discussion 1171-2. doi: 10.1016/j.jpedsurg.2009.02.022

46. Partridge EA, Peranteau WH, Rintoul NE, Herkert LM, Flake AW, Adzick NS, et al. Timing of repair of congenital diaphragmatic hernia in patients supported by extracorporeal membrane oxygenation (ECMO). J Pediatr Surg. (2015) 50:260-2. doi: 10.1016/j.jpedsurg.2014.11.013

47. Kays DW, Islam S, Larson SD, Perkins J, Talbert JL. Long-term maturation of congenital diaphragmatic hernia treatment results. Ann Surg. (2013) 258:63845. doi: 10.1097/SLA.0b013e3182a53c49

48. Yoder BA, Lally PA, Lally KP, Congenital Diaphragmatic Hernia Study Group. Does a highest pre-ductal O2 saturation $<85 \%$ predict nonsurvival for congenital diaphragmatic hernia? J Perinatol. (2012) 32:947-52. doi: 10.1038/jp.2012.18

49. Prabhu S, Mattke AC, Anderson B, McBride C, Cooke L, Karl T, et al. Repair of congenital diaphragmatic hernia during extracorporeal life support: experience with six neonates. ANZ J Surg. (2016) 86:711-6. doi: 10.1111/ans.13466

50. Dassinger MS, Copeland DR, Gossett J, Little DC, Jackson RJ, Smith SD, et al. Early repair of congenital diaphragmatic hernia on extracorporeal membrane oxygenation. J Pediatr Surg. (2010) 45:693-7. doi: 10.1016/j.jpedsurg.2009.08.011

51. Fallon SC, Cass DL, Olutoye OO, Zamora IJ, Lazar DA, Larimer EL, et al. Repair of congenital diaphragmatic hernias on Extracorporeal Membrane Oxygenation (ECMO): does early repair improve patient survival? J Pediatr Surg. (2013) 48:1172-6. doi: 10.1016/j.jpedsurg.2013. 03.008

52. Kays DW, Talbert JL, Islam S, Larson SD, Taylor JA, Perkins J. Improved survival in left liver-up congenital diaphragmatic hernia by early repair before extracorporeal membrane oxygenation: optimization of patient selection by multivariate risk modeling. J Am Coll Surg. (2016) 222:459-70. doi: 10.1016/j.jamcollsurg.2015.12.059

53. Extracorporeal Life Support Organization. ECLS Registry Report International Summary January, 2018. Ann Arbor, MI (2018).
54. Reiterer F, Resch E, Haim M, Maurer-Fellbaum U, Riccabona M, Zobel $\mathrm{G}$, et al. neonatal extracorporeal membrane oxygenation due to respiratory failure: a single center experience over 28 years. Front Pediatr. (2018) 6:263. doi: 10.3389/fped.2018.00263

55. Ijsselstijn $\mathrm{H}$, van Heijst AFJ. Long-term outcome of children treated with neonatal extracorporeal membrane oxygenation: increasing problems with increasing age. Semin Perinatol. (2014) 38:114-21. doi: 10.1053/j.semperi.2013.11.009

56. Madderom MJ, Reuser JJCM, Utens EMWJ, van Rosmalen J, Raets M, Govaert P, et al. Neurodevelopmental, educational and behavioral outcome at 8 years after neonatal ECMO: a nationwide multicenter study. Intens Care Med. (2013) 39:1584-93. doi: 10.1007/s00134-013-2973-1

57. Schiller RM, Madderom MJ, Reuser JJCM, Steiner K, Gischler SJ, Tibboel D, et al. Neuropsychological follow-up after neonatal ECMO. Pediatrics. (2016) 138:e20161313. doi: 10.1542/peds.2016-1313

58. Walleyo A, Debus A, Kehl S, Weiss C, Schönberg SO, Schaible T, et al. Periodic MRI lung volume assessment in fetuses with congenital diaphragmatic hernia: prediction of survival, need for ECMO, and development of chronic lung disease. AJR Am J Roentgenol. (2013) 201:419-26. doi: 10.2214/AJR.12.8655

59. Spoel M, Laas R, Gischler SJ, Hop WJC, Tibboel D, de Jongste JC, et al. Diagnosis-related deterioration of lung function after extracorporeal membrane oxygenation. Eur Respir J. (2012) 40:1531-7. doi: 10.1183/09031936.00189911

60. IJsselstijn H, Hunfeld M, Schiller RM, Houmes RJ, Hoskote A, Tibboel D, et al. Improving long-term outcomes after extracorporeal membrane oxygenation: from observational follow-up programs toward risk stratification. Front Pediatr. (2018) 6:177. doi: 10.3389/fped.2018.00177

Conflict of Interest Statement: The authors declare that the research was conducted in the absence of any commercial or financial relationships that could be construed as a potential conflict of interest.

Copyright $\odot 2019$ Rafat and Schaible. This is an open-access article distributed under the terms of the Creative Commons Attribution License (CC BY). The use, distribution or reproduction in other forums is permitted, provided the original author(s) and the copyright owner(s) are credited and that the original publication in this journal is cited, in accordance with accepted academic practice. No use, distribution or reproduction is permitted which does not comply with these terms. 